\title{
Selection of Sustainable Food Waste Valorisation Routes: A Case Study with Barley Field Residue
}

\author{
Jamie Stone ${ }^{1}$ (D) $\cdot$ Guillermo Garcia-Garcia $^{1}$ (I) $\cdot$ Shahin Rahimifard ${ }^{1}$
}

Received: 9 March 2019 / Accepted: 23 September 2019 / Published online: 23 October 2019

(c) The Author(s) 2019

\begin{abstract}
Purpose It is increasingly accepted in the food and drink manufacturing sector that there is a need to manage unavoidable food waste more sustainably. Yet to do so requires careful balancing of environmental, social and economic performance of any given treatment method alongside its technological maturity and alignment with that company's wider business goals. The purpose of this article is to apply a novel Sustainable Waste Valorisation Identification (SWaVI) framework which considers these criteria to a case study with Molson Coors to identify whether the current strategy of using In Field Barley Straw Residue as animal feed is the most sustainable.

Methods Data was collected via a series of interviews with Molson Coors in spring 2017. Data analysis used a hybrid approach combining Cost-Benefit Analysis and Life-Cycle Assessment with a weighted summation variant of Multi-Criteria Decision Analysis to facilitate comparison of supercritical $\mathrm{CO}_{2}$ extraction of wax from straw, with the current strategy of selling that straw as animal feed.

Results Application of the SWaVI framework suggests that supercritical $\mathrm{CO}_{2}$ extraction of wax from straw offers a slightly worse Net Present Value compared to sale as animal feed ( $£ 89.1$ million compared to $£ 95.3$ million) but superior social impacts, technological maturity and alignment with company goals making it superior overall.

Conclusions Whilst the supercritical $\mathrm{CO}_{2}$ extraction of wax offers the best sustainability and business case performance for Molson Coors, a range of other factors such as long-term market demand, alignment with relevant legislation, and displacement effects on supply chain stakeholders must be considered.
\end{abstract}

\section{Graphic Abstract}

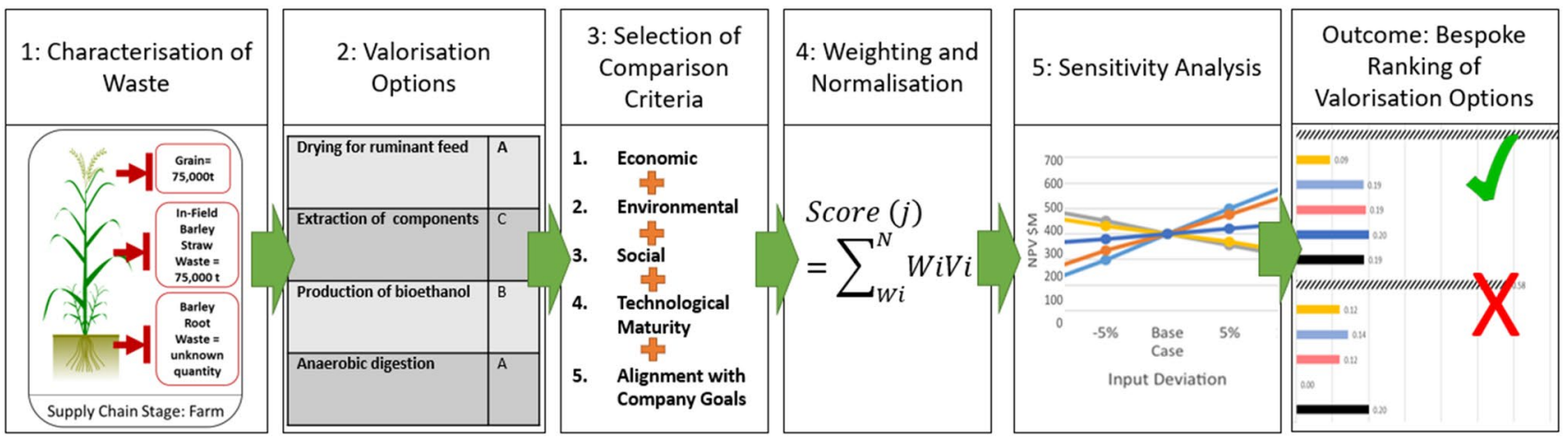

Keywords Food waste valorisation $\cdot$ Sustainability $\cdot$ Cost-benefit analysis $\cdot$ Brewing $\cdot$ Barley straw

Electronic supplementary material The online version of this article (https://doi.org/10.1007/s12649-019-00816-5) contains supplementary material, which is available to authorized users.

Extended author information available on the last page of the article 


\section{Statement of Novelty}

This article presents a novel framework designed to facilitate the initial identification of the most sustainable food waste valorisation options available to companies in the food manufacturing sector.

\section{Introduction}

It is a well-known fact that approximately one third of all food produced globally for human consumption is lost or wasted. This is not just a developing world problem. For instance in the UK approximately 10 million tonnes (Mt) of food and drink, with a value of $£ 17$ billion, is wasted each year post-farm-gate across the supply chain [1]. In addition to being financially damaging, this waste can lead to significant, yet ultimately needless, environmental impact through emissions to air, land and water as well as biodiversity loss at all stages of production [2]. The issue is so significant globally, that the United Nations Sustainable Development Goal 12.3 calls for the halving of per capita global food waste at the retail and consumer levels and a reduction of food losses along production and supply chains [3].

The significance of food waste is not only a challenge at a national level, but also at an individual company level. In the UK food and drink sector whilst there were 6700 micro, small and medium sized enterprises (SMEs) in 2017, $97 \%$ of these accounted for just $19 \%$ of the sector's turnover, indicating the tight profit margins faced in a supply network dominated by a small number of large manufacturers (and of course, the large retailers they supply) [4]. The majority of these SMEs are specifically involved in the food and drink manufacturing sector, which in 2015 accounted for $2.4 \mathrm{Mt}$ of food waste and surplus (including both unavoidable and avoidable waste/surplus) [5]. This represents a significant economic loss ( $4.2 \%$ of sales for the sector) to these companies, so much so, that the UK based charity, Waste Resource Action Plan (WRAP), in a study spanning 700 companies across 17 countries, found that $99 \%$ of companies gained at least a $£ 14$ return for every $£ 1$ invested in food waste prevention and management [6]. It is easy to understand then why a number of companies have signed up to the voluntary Courtauld Commitments organized by WRAP with the aim of reducing food waste in the UK supply chain via a combination of techniques such as measuring waste, training staff, improving inventory management and changing packaging [7].

As successful as such waste reduction goals can be, it must be kept in mind that $1.34 \mathrm{Mt}$ of the food and drink manufacturing waste is not practically avoidable [5]. With disposal methods such as landfill being costly and even the current widespread use of anaerobic digestion being unfavorable according to the food waste hierarchy, it is unsurprising that ways of recovering energy, nutrients and other high value compounds from food waste, ideally for human consumption, are a major area of contemporary interest, under the label of 'food waste valorisation' [8-11]. However, for most food waste streams, there will be more than one possible valorisation option, and each will likely have a plethora of possible economic, social and environmental impacts in addition to varying levels of technologically maturity and alignment with company strategic goals/image $[12,13]$. Impacts in these areas will determine how appealing, and ultimately sustainable, each possible valorisation is to a given company and therefore need to be assessed, albeit with the sometimes-limited expertise, time and resources available to smaller food and drink manufacturers.

As identified by Stone et al. [14], existing research in food waste valorisation has not covered all of the aforementioned areas and tends to focus on single criteria, for example, environmental impact via Life-Cycle Assessment (LCA), or cost via Life-Cycle Costing (LCC) and Cost-Benefit Analysis (CBA). Multi-Criteria Decision Analysis (MCDA) approaches have been shown by some authors to enable comparison of a broad range of similar criteria to those outlined above, without the need for high levels of technical expertise, provided the user is guided closely in the parameters they can select $[15,16]$. Therefore, using a weighted summation MCDA approach, the aforementioned authors developed the 'Sustainable Waste Valorisation Identification' (SWaVI) framework which characterises a company's food waste, suggests appropriate valorisation techniques, guides the selection of appropriate evaluation criteria and facilitates the collection and analysis of data on these criteria so as to make a recommendation on which valorisation approach is best suited to the company at hand. Whilst the framework was successfully demonstrated in one food and drink manufacturing sector, there is significant scope to apply this framework in different industrial contexts and particularly to explore systemic barriers and potential unintended consequences at a supply chain level and this is the aim of this paper.

This paper presents the application of the SWaVI framework in assessing the most sustainable valorisation options for the management of in-field barley straw waste (IFBSW) in the UK. This is a significant waste stream from a UK perspective with barley being the second largest cereal crop behind wheat, with 6.5-7.5 million tonnes produced annually for human consumption, including brewing and distilling and also as animal feed [17]. Whilst this paper focuses on the UK, it should be noted that, globally, 140 million 
tonnes of barley are produced annually, making it one of the most widely produced grains and as such, the understanding of how IFBSW waste is generated and how it can be valorized is relevant worldwide [18]. This paper begins by outlining the methodology behind data collection and application of the SWaVI framework, before presenting the case study context and findings, discussing the ramifications of the findings at a company and supply chain level and culminating in concluding remarks.

\section{Methodology}

This research project consisted of the application of the SWaVI framework via a case study with Molson Coors Brewing Co. (UK), referred to from now on as Molson Coors, who are one of the biggest users of barley in the UK and are associated with significant IFBSW. For conciseness, only an outline of the framework stages and a description of how it was applied to Molson Coors is provided in this methodology. Full details, including the literature review, the rationale behind the SWaVI framework that stemmed from this review, and a full guide to the application of this framework can be found in Stone, Garcia and Rahimifard (2019) [14]. The SWaVI framework consists of five stages as outlined in Fig. 1.

The goal of the framework is to enable companies of any size to identify and compare different strategies for valorising food waste, based on economic, social and environmental impact, technological maturity and alignment with company goals. The first stage concerns the modelling of where in a company's operations food waste is created, to what volumes and timescales it is created and what relevant

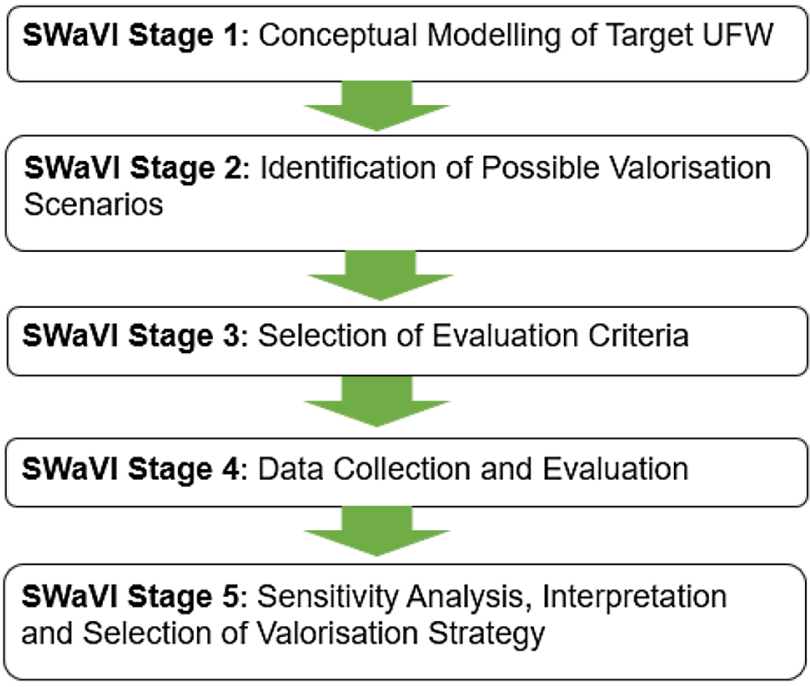

Fig. 1 'Sustainable Waste Valorisation Identification' framework overview legislation and wider stakeholder interests are involved. The second stage involves the identification of potential valorisation scenarios by comparing the characteristics of the waste stream identified in Stage 1 with a taxonomy of valorisation possibilities based upon the AgroCycle database [19]. In Stage 3, the economic, social, environmental, technological maturity and company goal alignment indicators to evaluate each of the previously selected possible valorisation scenarios are selected. Stage 4 consists of the collection of data for each of the evaluation criterion selected and the processing of these data using a weighted summation variant of MultiCriteria Decision Analysis to facilitate comparison of each valorisation scenario according to which performs best for the company at the present snap shot in time. For a description of why this methodology was chosen, please refer to Stone et al. (Sects. 3.6 and 3.7) [14] and for guidance on its application, please refer to the supplementary information document. The final section of the SWaVI framework describes the process for applying sensitivity analysis to explore how minor variations in the values of each of the evaluation criteria, for example, changes in energy price and value of the end-product, over time, may lead to different valorisation scenarios being preferred.

Data were collected from Molson Coors mainly through site visits in spring 2017. In these visits, staff with an understanding of the creation and management of IFBSW were interviewed, using a questionnaire for guidance, to identify sources, volumes and timings of waste, current food waste management strategies and logistics associated with these practices, as well as linked value chain stakeholders and legislation. The guiding questionnaire included basic questions to guide the conversation around the areas described above, but additional questions were asked during this interview to explore some of these aspects in more detail.

Additional, mostly quantitative, data were collected at later stages by email communication. This procedure enabled the generation of a precise definition of the industrial problem to be tackled and the proposition of two different valorisation scenarios to be considered and appropriate evaluation metrics for each. The data pertaining to each of the chosen evaluation criterion was then collected in an evaluation matrix and augmented/analyzed as outlined in the supplementary information document (Sect. 2).

Therefore, all information presented in this paper can be considered to have been provided (or calculated from data provided) by Molson Coors, unless another reference is given. Molson Coors' data on sources, volumes and timings of waste, food waste management strategies and logistics, stakeholders and legislation, remained reasonably constant for several years, with only the actual volumes of waste increasing or decreasing on a monthly basis (mostly due to different production levels driven by consumer demand). The proportions of different waste streams, raw materials 
and final products remained constant and thus, the data and results presented in this paper are representative of Molson Coors' current and near past/future activities. To overcome the significant difference in scales of the evaluation criteria, the weighted summation method (WSM), as described by Herwijnen, was applied to the values recorded in the evaluation matrix (please see the supplementary information document for guidelines on the use of this technique in this paper) [20]. In this way, the different environmental, social, economic, technological maturity and company goal alignment indicators for each valorisation scenario are standardized based upon their position in relation to the highest and lowest recorded values for that criterion which is expressed on a scale of $0-1$. The standardized values for each evaluation criterion and sub-criterion are then assigned an equal weight and summed to give a final score for each valorisation strategy being compared. As a final step, sensitivity analysis was then carried out to explore the stability of all key inputs to each scenario over their projected lifespan to inform a final recommendation for which valorisation scenario to implement.

\section{Case Study Results}

A case study with Molson Coors, a multinational brewing company that produces beer brands such as Carling, Coors Light and Cobra Beer, is presented in this section. This case study focuses upon their main manufacturing site in Burton upon Trent in Staffordshire, which produces approximately $6.5 \mathrm{Mhl}$ of beer per year, representing around $75 \%$ of their total beer production in the UK. Currently, around 75,000 tonnes of IFBSW per year could be allocated to Molson Coors' manufacturing activities in Burton upon Trent, representing one of the biggest single sources of such waste in the UK [21]. As outlined in the Methodology Section, the case study proceeded in the form of a step-wise application of each of the SWaVI stages, beginning with conceptual modelling of the target food waste.

\section{SWaVI Stage 1: Conceptual Modelling of Target Food Waste}

The first step in the conceptual modelling was to identify where in their value chain Molson Coors had influence over waste generation and which of these areas should be the focus of valorisation efforts. The case study process identified that through their relations with supply chain partners, Molson Coors had influence over waste arising in-field postharvest, in the malting process and within the various brewing steps at Molson Coors' Burton upon Trent facility as outlined in Fig. 2.

Beginning by analysing waste arising at a farm level, much of the barley grown for Molson Coors is produced in the eastern counties of Lincolnshire and Yorkshire. The barley plant can typically be divided into three roughly equal components: grain, straw and roots. Grain is the only part that is of value in the brewing process, with Molson Coors receiving 75,000 ton annually. Being of much less value, typically, the root is ploughed back into the soil on site and the straw is shipped to farms in the east for use as feed supplement material at a profit of about $£ 50 / t$ of straw for Molson Coors [21]. Moving on to the malting stage, here typically 4000 tons annually are lost as waste, with a further volume of approximately 4000 tons of water being lost in the process and this small volume of malt waste is typically sent for animal feed. Once on site at Molson Coors, the malt goes through the process of mashing, cooling, fermentation, maturation and final packaging to produce saleable beer. During this process, by far the largest source of waste is the spent grain left at the end of the mashing process which totals around 76,000 ton annually. However, 7700 tons of trub and

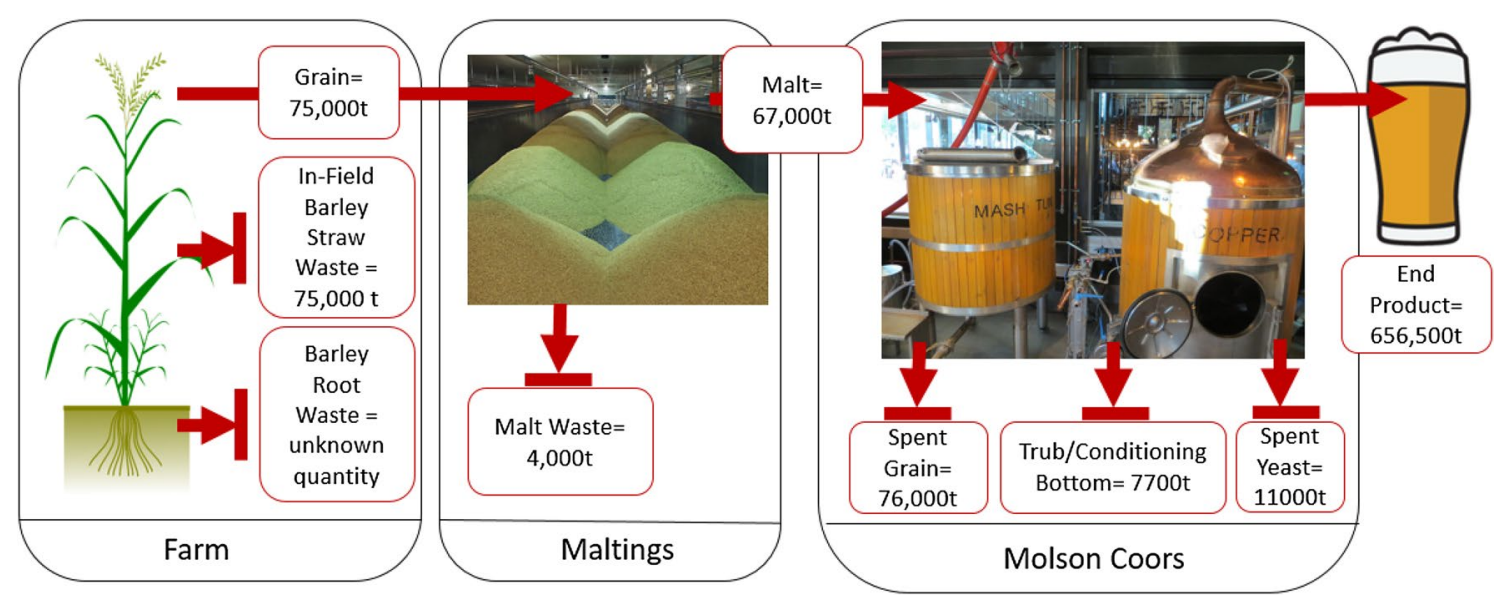

Fig. 2 Breakdown of waste arising in the Molson Coors supply chain. Data from Garcia et al. [21] 
conditioning bottom, and 11,000 tons of spent yeast are also produced during the fermentation/maturation process.

Trub and conditioning bottom are sent for animal feed, filter waste is sent to sewage and compost and spent yeast is marketed for human consumption under the popular brand of Marmite ${ }^{\circledR}$. The output for this process is approximately 6.5 Mhl of beer for sale to Molson Coors customers. Clearly, there are a number of waste streams arising from Molson Coors' supply chain, with some currently treated in a more profitable and sustainable way than others, for example, the use of spent grain for Marmite ${ }^{\circledR}$ production represents relatively high economic return and sustainability, albeit for a relatively low volume waste stream, whilst the sale of the much higher volume IFBSW for animal feed represents poorer economic return/sustainability.

With this in mind, this case study focused on the largest volume waste streams that were currently generating minimal economic return for Molson Coors and these were IFBSW and spent grain from the brewing process, together accounting for $80 \%$ of Molson Coors supply chain waste. Upon discussion with Molson Coors, they expressed a preference in exploring IFBSW. Furthermore, analysis of the yearly generation of IFBSW revealed that whilst this waste source was higher from June to December, it was still available in substantial quantities all year round, thus making it a reliable feedstock for valorisation (see Fig. 3). Having identified IFBSW as a prime candidate for valorisation from Molson Coors perspective, the next step was to explore how changing the way this waste is managed would impact existing supply chain stakeholders and whether there were any legal considerations such as environmental permitting, taxes or subsidies that a change in management of IFBSW would affect. In terms of stakeholder analysis with regard to the effects of potentially removing IFBSW from the market, it was identified that farmers currently receiving IFBSW as feed supplement would likely be able to find alternatives (such as different types of straw) at comparable prices [22, 23]. It is also unlikely that removing IFBSW from its current use as a feed supplement would impact on existing environmental emissions permits as no new generation of waste to land would be involved. Currently, under Common Agricultural Policy (CAP) guidelines, a change in how IFBSW was used would not affect incentives delivered [24]. However, it is possible that any equipment required for valorisation would benefit from capital allowances on energy efficient appliances and furthermore, could be eligible for various incentives under a new post-Brexit UK Agriculture Bill currently being debated in parliament $[25,26]$.

\section{SWaVI Stage 2: Identification of Possible Valorisation Scenarios}

The first step in identifying possible valorisation scenarios for Molson Coors' IFBSW was to explore current performance. From an environmental perspective, treatment of IFBSW as animal feed supplement is mid-way up the food waste hierarchy, with low economic return for Molson Coors . With this in mind, a number of valorisation options were considered based upon the SWaVI framework taxonomy (see

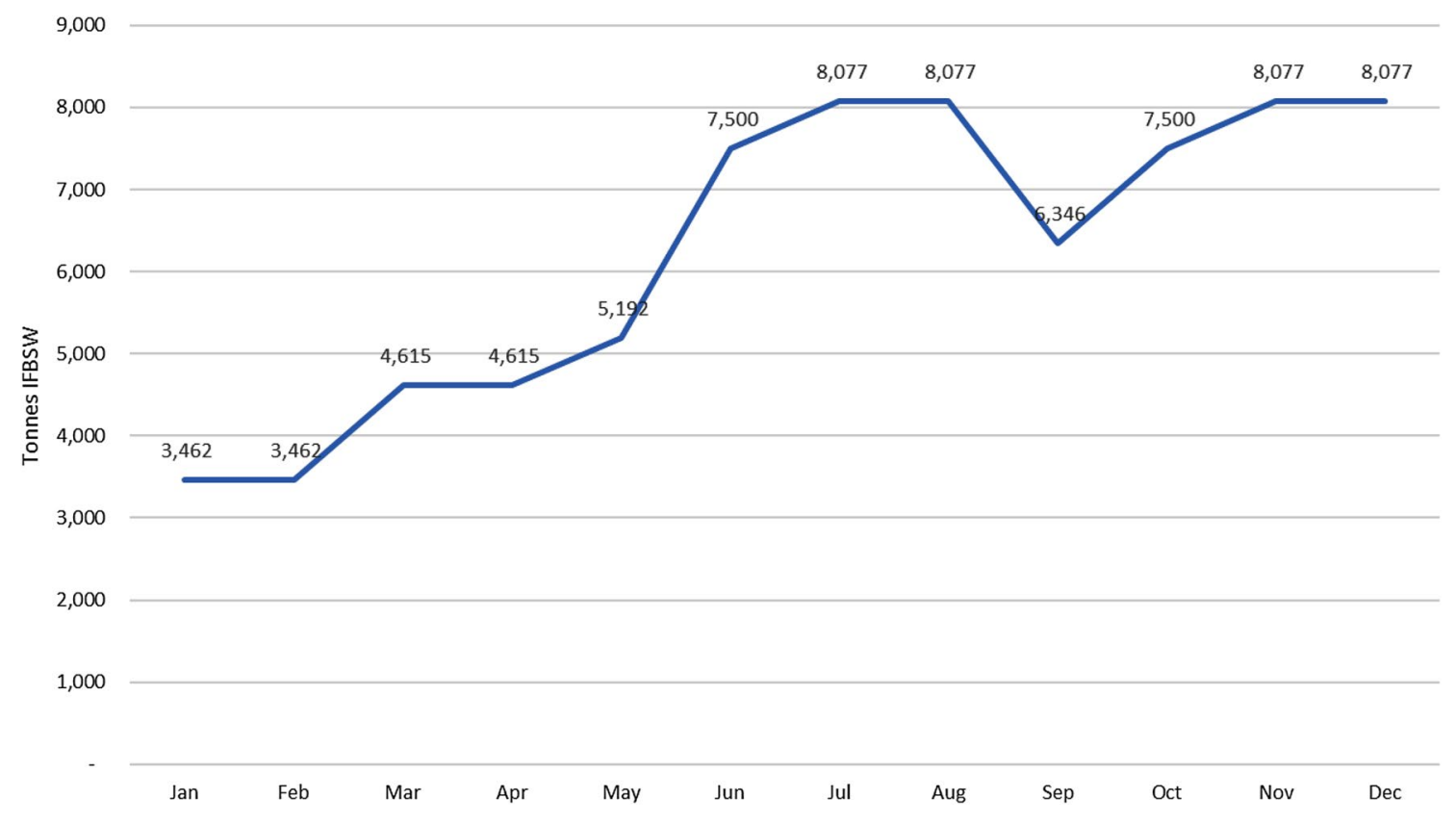

Fig. 3 Seasonal generation of In Field Barley Straw Waste 

routes for barley straw (compiled using data from the AgroCycle database, 2016 [19])
Table 1 Possible valorization

\begin{tabular}{ll}
\hline Barley & \\
\hline Husk/bran & \\
Drying for ruminant feed & A \\
Extraction of valuable & C \\
components (e.g. cel- & \\
lulose, protein, starch) & \\
Production of bioethanol & B \\
Anaerobic digestion & A \\
Straw & \\
Drying for ruminant feed & A \\
Extraction of valuable & C \\
components (e.g. cel- & \\
lulose, protein, starch) & \\
Production of bioethanol & B \\
Anaerobic digestion & A \\
\hline
\end{tabular}

excerpt in Table 1) which categorizes possible valorisation options according to one of three levels:

(A) Low value, to be used when either: (i) ability to invest in valorisation is low or (ii) the goal is sustainable disposal rather than profit.

(B) Bioethanol has the potential for high value returns but requires year-round reliably high feedstock volumes, and the ability to offset potential transport costs and environmental impacts.

(C) Highest value but requires high volumes, stable annual production and significant capital investment.

Based upon this, anaerobic digestion was discounted because the economic returns were unlikely to be better than what was already achieved through sale as animal feed supplement and also because other alternatives such as wax extraction can be used for food purposes which is more valuable according to the food waste hierarchy. Conversion to fuel via bioethanol was also considered but rejected when it was identified that extraction of high value compounds, in the form of wax, could potentially offer higher economic returns and higher ranking on the food waste hierarchy [27]. In terms of why wax was selected, it is important to consider the composition of IFBSW. IFBSW consists primarily of cellulose (56.2 wt\%), lignin (up to $23 \mathrm{wt} \%$ ) and hemicellulose $(7 \mathrm{wt} \%)$ with much smaller volumes of waxes, protein, sugars, salts and ash making up the remainder [19]. With this composition, straw is relatively high in terms of calorific energy and is typically used as feed for ruminants or bedding, but can also be used in a range of industrial applications, including production of bio-based building materials [28] and production of xylooligosaccharides [29]. However, in all cases the value derived is still relatively low. Another alternative would be to focus on the extraction of cellulose, which in its microcrystalline form has a global market value of USD 9.27 billion in 2018. However, whilst cellulose extraction effectively prevents all other uses for the IFBSW, it is possible to extract the wax using a novel supercritical $\mathrm{CO}_{2}\left(\mathrm{sCO}_{2}\right)$ extraction process, whilst still leaving a dried straw suitable for animal feed [30]. Extraction of wax, on the other hand, has an additional advantage of being very valuable as a component in plastic, rubber, use in cosmetic and toiletries and even for human consumption in the form of varieties such as carnauba wax (Type 3 grade) [31].

It is little surprise then that the global market for wax was valued at $\$ 9,322$ million in 2016 , and it is anticipated to increase to $\$ 11,780$ million by $2023[32,33]$. The wax obtained from valorisation of barley straw following this process would be apt for human consumption, just like carnauba wax, thus making this the most optimal valorisation approach according to the food waste hierarchy. $\mathrm{sCO}_{2}$ wax extraction is also relatively straightforward, consisting of sequential stages of milling, pelletisation, cooling and drying, $\mathrm{sCO}_{2}$ extraction and separations followed by a final pelletisation stage meaning that, although some capital costs and staff training would be involved, it is feasible that a company could perform the process in house without reliance on an 3rd party biorefinery operation [30]. As a result, the valorisation scenarios selected for comparison in this case study were sale of all 75,000 ton of IFBWS for feed supplement (i.e. current treatment option) and $\mathrm{sCO}_{2}$ extraction of wax followed by sale for animal feed of the remaining IFBWS.

\section{SWaVI Stage 3: Selection of Evaluation Criteria}

The SWaVI framework contains a purpose-built taxonomy of evaluation criteria, from which a user can choose, to enable comparison of different valorisation scenarios based upon their economic, social, environmental, and brand image impact, as well as their technological suitability (see Table 2) based upon a detailed review carried out by Stone et al. [14]. The first step was to identify the scope and boundaries within which selected criteria would be applied. Only impacts directly associated with either the $\mathrm{sCO}_{2}$ extraction of wax or the sale of IFBSW as a feed supplement were considered. Specifically, this included all economic costs, environmental and social performance, technological suitability of associated processes and fit with brand strategy of each scenario at set up (including the cost of $\mathrm{sCO}_{2}$ extraction equipment and other capital expenses) and day-to-day running (processing and staff costs). More details of the definition of the scope and assumptions made to model these processes, particularly for the environmental impact assessment, can be found in a previous study by Garcia and Rahimifard [54]. Within these boundaries, the selected evaluation criteria were refined as follows. With regard to the economic criteria, the $\mathrm{sCO}_{2}$ extraction scenario would 
Table 2 Evaluation criteria taxonomy

\begin{tabular}{|c|c|c|c|}
\hline Type of criteria & Sub-criteria & Units & References \\
\hline \multirow[t]{7}{*}{ Economic Viability } & Raw Material Cost (RMC) & $£ /$ ton & {$[30,34]$} \\
\hline & Capital Costs (e.g. land/equipment) (CC) & $£ /$ item & {$[30,34,35]$} \\
\hline & $\begin{array}{l}\text { Operational \& Maintenance Costs (e.g. depre- } \\
\text { ciation, repairs, labor) (OMC) }\end{array}$ & $£ /$ hour & {$[30,34,35]$} \\
\hline & $\begin{array}{l}\text { Sales Revenue (both primary and by/co-prod- } \\
\text { ucts) (SR) }\end{array}$ & $£ /$ item or ton & {$[30,34-36]$} \\
\hline & Utilities Cost (e.g. energy and water) (UC) & $£$ /unit & {$[30,34]$} \\
\hline & Government Subsidies/Incentives (GSI) & $£ /$ unit of capacity & {$[30,34]$} \\
\hline & $\begin{array}{l}\text { Net Present Value (sum of all of the } \\
\text { above + discounting) (NPV) }\end{array}$ & $£$ & {$[30,34]$} \\
\hline \multirow[t]{9}{*}{ Environmental Sustainability } & Energy, Water and Mineral Efficiency (EWME) & Volume consumed/ton product & {$[35,37,39]$} \\
\hline & Climate Change Potential (CCP) & $\mathrm{kg} \mathrm{CO}_{2}$-eq & {$[37,38,40]$} \\
\hline & Human Toxicity Potential (HTP) & CTUh/mPE year & {$[37,38,40]$} \\
\hline & $\begin{array}{l}\text { Photochemical Ozone Formation Potential } \\
\text { (POFP) }\end{array}$ & kg NMVOC eq & {$[37,38,40]$} \\
\hline & Acidification Potential (AP) & $\mathrm{AE} / \mathrm{mPE}$ year & {$[37,38,40]$} \\
\hline & Eutrophication Potential (EP) & $\mathrm{kg} \mathrm{N}$ eq./mPE year & {$[37,38,40]$} \\
\hline & Ozone Depletion Potential (ODP) & kg CFC-11-eq./mPE year & {$[37,38]$} \\
\hline & Ecotoxicity Potential (EP) & CTUe/mPE year & {$[37,38]$} \\
\hline & Land Use Change (LUC) & $\mathrm{m}^{2} \mathrm{a}$ & {$[37,38]$} \\
\hline \multirow[t]{5}{*}{ Social Sustainability } & Social Acceptability (SA) & $++/-$ & {$[41,42]$} \\
\hline & Odors Generation (OG) & $++/-$ & [42] \\
\hline & Noise Creation (NC) & $\mathrm{dB}$ & {$[42-45]$} \\
\hline & Job Creation (JC) & Number of people benefitted/ton & [42-46] \\
\hline & Traffic Generation (TG) & Number of vehicles/ton of FW & {$[42,47,48]$} \\
\hline \multirow[t]{3}{*}{ Technological Maturity } & Technology Readiness Level (TRL) & $\begin{array}{l}1-9(1=\text { basic principles observed, } 9=\text { actual } \\
\text { system proven })\end{array}$ & {$[49,50]$} \\
\hline & Integration Readiness Level (IRL) & $\begin{array}{l}1-7(1=\text { technologies can connect but not } \\
\text { integrate, } 7=\text { seamless integration })\end{array}$ & {$[50,51]$} \\
\hline & Demand Readiness Level (DRL) & $\begin{array}{l}1-9(1=\text { feeling something is missing, } 9=\text { com- } \\
\text { pleted answer to actual need of market })\end{array}$ & {$[50,52]$} \\
\hline \multirow[t]{3}{*}{ Alignment with Company Goals } & Fit with Strategy (FS) & $1-5(1=$ poor, $3=$ moderate, $5=$ strong $)$ & {$[53]$} \\
\hline & Fit with Brand Image (FBI) & $1-5(1=$ poor, $3=$ moderate, $5=$ strong $)$ & {$[53]$} \\
\hline & Fit with Company Expertise (FCE) & $1-5(1=$ poor, $3=$ moderate, $5=$ strong $)$ & [53] \\
\hline
\end{tabular}

involve significant capital investment to purchase equipment as well as lifespan running costs. Therefore, Raw Material Cost (RMC), Capital Costs (CC), Operational \& Maintenance Costs (OMC), Sales Revenue (SR), Utilities Cost (UC), and Government Subsidies/Incentives (GSI) were selected for inclusion. Additionally, a Cost-Benefit Analysis was performed on these criteria so as to generate a discounted Net Present Value which took into account the fact that returns in the present are generally preferred over those that would take a long time to be realized. Whilst it is clear that set-up costs for the feed supplement scenario are much lower, there are still set-up and running costs associated and so these criteria were deemed suitable for both scenarios. In terms of environmental evaluation criteria, it was identified that both the feed supplement and $\mathrm{sCO}_{2}$ extraction process had the potential to result in emissions to air, water and land for which Molson Coors would be responsible. Therefore, Climate Change Potential (CCP), Human Toxicity Potential (HTP), Photochemical Ozone Formation Potential (POFP), Acidification Potential (AP), Eutrophication Potential (EP), Ozone Depletion Potential (ODP), and Ecotoxicity Potential (EP) were identified for inclusion. Land Use Change (LUC) was not included as neither the $\mathrm{sCO}_{2}$ extraction or feed supplement scenarios, within the boundaries set, were felt to drive this indicator. Additionally, whilst Energy, Water and Mineral Efficiency (EWME) was identified as being relevant, it was not included due to challenges in obtaining suitable data from Molson Coors. In terms of social evaluation criteria, Social Acceptability (SA), Odor Generation (OG), Noise Creation (NC), Job Creation (JC) and Traffic 
Generation (TG) were identified as being relevant to the $\mathrm{sCO}_{2}$ and feed supplement sale scenarios alike. Likewise, with regard to technological fit of each scenario, Technology Readiness Level (TRL), Integration Readiness Level (IRL) and Demand Readiness Level (DRL) were all identified as being appropriate due to the fact that $\mathrm{sCO}_{2}$ extraction, as a new process, involved not only the use of new technologies, but also their integration with broader value chains and fit with market demand for a new product. Finally, in order to establish how well the $\mathrm{sCO}_{2}$ extraction scenario aligned with Molson Coors long-term company vision, Fit with Strategy (FS), Fit with Brand Image (FBI) and Fit with Company Expertise (FCE) were selected.

\section{SWaVI Stage 4: Data Collection and Evaluation}

This stage concerned the generation of values for each evaluation criterion selected in Stage 3 under the $\mathrm{sCO}_{2}$ extraction of wax scenario and the current scenario of sale as animal feed supplement. Results are shown in Table 2, in both cases, referring to valorisation of all 75,000 tons of IFBSW generated from Molson Coors' activities annually, which is the functional unit for all five criteria. These results were scaled up from data obtained for 90-kg batches of IFBSW, as reported by $\mathrm{Sin}$ et al. [29]. Three parallel lines processing 90-kg batches are needed to valorise 75,000 tons of IFBSW per year. In order to arrive at the values provided in Table 3 , a significant amount of data conversion and processing was required, and for conciseness, details on these steps are described in full in Sect. 2 of the Supplementary Information document. Only the actual results described in Table 3 are discussed here. Moving from left to right, starting with economic criteria, we begin with the sub-criterion of 'Net Present Value'. A detailed CBA of set-up and running costs associated with each valorisation scenario was performed considering costs associated with equipment purchasing, consumables and staff salaries against revenue from the sale of wax and animal bedding based upon current market values. Building costs and transport costs were excluded due to difficulties in obtaining reliable data. In this way, the Net Present Value returned for the feed supplement scenario is slightly higher at almost $£ 93.5$ million as opposed to $£ 89.1$ million for the $\mathrm{sCO}_{2}$ extraction scenario. This is predominantly because, whilst the $\mathrm{sCO}_{2}$ extraction scenario generated significant extra revenue from the sale of wax, it also required substantial set-up and salary costs which were not faced by the comparatively simpler process of baling and selling IFBSW as feed supplement.

Life-Cycle Assessment was performed for both scenarios using the life-cycle impact assessment method ILCD 2011 Midpoint + V1.10/EC-JRC Global, equal weighting/Characterisation/Excluding infrastructure processes, as explained in detail by Garcia and Rahimifard [54]. For the $\mathrm{sCO}_{2}$ extraction process, measurements were made for the energy and water consumed at each step of the process of extracting wax from a 90-kg batch of barley straw residue. For the same reason that transport and building costs could not be calculated for NPV, it was difficult to include

Table 3 Completed evaluation matrix for feed supplement and $\mathrm{sCO}_{2}$ extraction of IFBSW

\begin{tabular}{|c|c|c|c|c|}
\hline Evaluation criteria & Sub-criteria & Unit & Feed supplement & ${ }_{\mathrm{s}} \mathrm{CO}_{2}$ extraction \\
\hline Economic & Net Present Value & $£$ & $95,385,353.6217$ & $89,085,090.0347$ \\
\hline \multirow[t]{7}{*}{ Environmental } & Climate Change Potential & $\mathrm{kg} \mathrm{CO}_{2}$-eq & 0 & 324 \\
\hline & Human Toxicity Potential & CTUh & 0 & 0.0001 \\
\hline & Photochemical Ozone Formation Potential & Kg NMVOC eq & 0 & 0.5100 \\
\hline & Acidification Potential & molecular $\mathrm{H}+\mathrm{eq}$ & 0 & 1.4000 \\
\hline & Freshwater Eutrophication Potential & $\mathrm{kg} \mathrm{P}$ eq & 0 & 0.0774 \\
\hline & Ozone Depletion Potential (ODP) & kg CFC-11-eq & 0 & 0 \\
\hline & Ecotoxicity Potential & CTUe & 0 & 828 \\
\hline \multirow[t]{5}{*}{ Social } & Social Acceptability & $+/++$ & ++ & ++ \\
\hline & Odor Generation & $+/++$ & ++ & + \\
\hline & Noise Creation & $\mathrm{dB}$ within $15 \mathrm{~m}$ & 80 & 85 \\
\hline & Job Creation & Total jobs & 0 & 6 \\
\hline & Traffic & No. of vehicles & 10 & 25 \\
\hline \multirow[t]{3}{*}{ Technological Maturity } & Technology Readiness & TRL Scale (1-9) & 9 & 9 \\
\hline & Integration Readiness & IRL Scale (1-7) & 1 & 7 \\
\hline & Demand Readiness & DRL Scale (1-7) & 9 & 9 \\
\hline \multirow[t]{3}{*}{ Alignment with Company Goals } & Strategy Fit & Likert Scale (1-5) & 3 & 5 \\
\hline & Brand Fit & Likert Scale (1-5) & 3 & 1 \\
\hline & Expertise Fit & Likert Scale (1-5) & 3 & 1 \\
\hline
\end{tabular}


transport and building related impacts in the calculation of environmental impact and these were therefore excluded from consideration in either scenario. For the feed supplement stage of each scenario, a score of zero environmental impact with regards to livestock consumption and decomposition of uneaten straw was recorded as Molson Coors were unable to supply the required data due to this impact occurring off-site. However, the authors feel that it is reasonable to assume that the environmental burdens for the two feeding scenarios would be equivalent because the volumes are virtually the same (i.e. $90 \mathrm{~kg}$ of IFBSW compared to $90.82 \mathrm{~kg}$ of post- $\mathrm{SCO}_{2}$ extraction barley residue). The difference in volume is simply caused by a higher moisture level in the post-s $\mathrm{CO}_{2}$ extraction barley residue. Also, the environmental impact associated with transportation of this feed would be virtually the same in both scenarios (e.g. same supplier, processing and customers, and since the volume of wax generated is very low compared to the volume of feed, environmental impacts associated to transportation of wax would be minimal, supporting the simplification made in this study of excluding the impacts and costs of transportation. This means that, the IFBSW animal feed scenario effectively achieved an environmental impact of zero, whilst the environmental impact is higher for the $\mathrm{sCO}_{2}$ extraction scenario ( 0.2 once weighted appropriately) because of the energy use and emissions associated with the process itself.

From a social impact perspective, Molson Coors identified that both scenarios had a high social acceptability as they produced useful products from by-products that would otherwise have gone to waste and with minimal negative environmental impact. In terms of odor generation, the feed supplement process faired best as whilst it is associated with some livestock odors that are released into the wider environment, the $\mathrm{sCO}_{2}$ extraction process generates some odor during milling and pelletisation, in addition to then being used as feed and subsequently generating livestock odors too. From a sound perspective, both scenarios scored similarly, with the noise from a combine harvester equating to $80 \mathrm{~dB}$ and the milling/pelleting machinery in the $\mathrm{sCO}_{2}$ extraction process generating an estimated $85 \mathrm{~dB}$. Both are just within the legal safe limits. However, the $\mathrm{sCO}_{2}$ extraction scenario is superior from a job creation perspective, employing six new staff members, whereas the feed supplement scenario does not require any extra staff than would already be employed as part of the harvest process. From a traffic generation perspective, whilst we did not know the exact length of journeys, based on advice from Molson Coors that 6-tonne trucks were most likely to be used, we could determine an average number of journeys likely required for each scenario. This was 12,500 for the feed supplement scenario and 14,696 for the $\mathrm{sCO}_{2}$ extraction scenario, the higher number being because the extracted wax and the pelletised barley straw for animal feed would require separate journeys to different destinations.

Moving on to the technological impact of each scenario, for the feed supplement scenario, Molson Coors identified that clearly the technology on farm for baling/preparing IFBSW suitable for feed supplement was completely tried and tested and also that demand for IFBSW at present was even higher than in previous years, generating a high demand readiness score. However, sale as feed supplement was very much a peripheral activity, taking place outside of Molson Coors' main facility and thus being poorly integrated. $\mathrm{sCO}_{2}$ extraction on the other hand would occur at their main Burton-upon-Trent site and so would by nature be more integrated and could, in future, be adapted to use other waste streams occurring from on-site brewing, thus gaining a higher integration readiness score. It was also identified that demand for carnauba wax, and particularly more sustainable replacements was high, thus resulting in a high demand readiness level [34]. However, the technology readiness for the $\mathrm{sCO}_{2}$ extraction process scores slightly less as, whilst the technology is ready to implement at a small industrial scale (as demonstrated by Attard et al. [34]), in order to process the full annual quota of IFBSW, the assumption was that three such lines would be required to run in parallel. This may not be the most efficient way for Molson Coors to run the operation but details on a working larger scale set up were unavailable, leading to concerns about technological readiness.

With regard to alignment with company fit, feed supplement achieved average scores for fit with strategy, brand and company expertise. This was because, in terms of strategy, disposal of IFBSW via feed supplement is a sustainable use of a waste that is fundamental to Molson Coors brewing activities. However, its economic returns are relatively low and feed supplement ranks lower on the waste hierarchy than extraction of wax and possible application in human food and for this reason, $\mathrm{sCO}_{2}$ extraction scored more highly. However, in terms of fit with brand image it was noted that $\mathrm{sCO}_{2}$ extraction of wax does not immediately fit within Molson Coors current brand portfolio. Whilst the same is true of feed supplement, this is also an external process with an established market Molson Coors would be conducting $\mathrm{sCO}_{2}$ extraction on site and would need to brand and establish a market base accordingly, thus meaning that $\mathrm{sCO}_{2}$ extraction scored very low in this criterion. Similarly, whilst the drying and baling of IFBSW for feed supplement is a process which Molson Coors' farmers are familiar with, new staff and expertise would need to be brought in for $\mathrm{SCO}_{2}$ extraction, thus resulting in the later scoring poorly in this area too.

Once scores for all criteria for each scenario were collected in this way they were normalized following the procedure outlined by Herwijnen [20]. Equal weighting was then applied to each of the evaluation criteria and the results 
Overall scores of the two valorisation scenarios

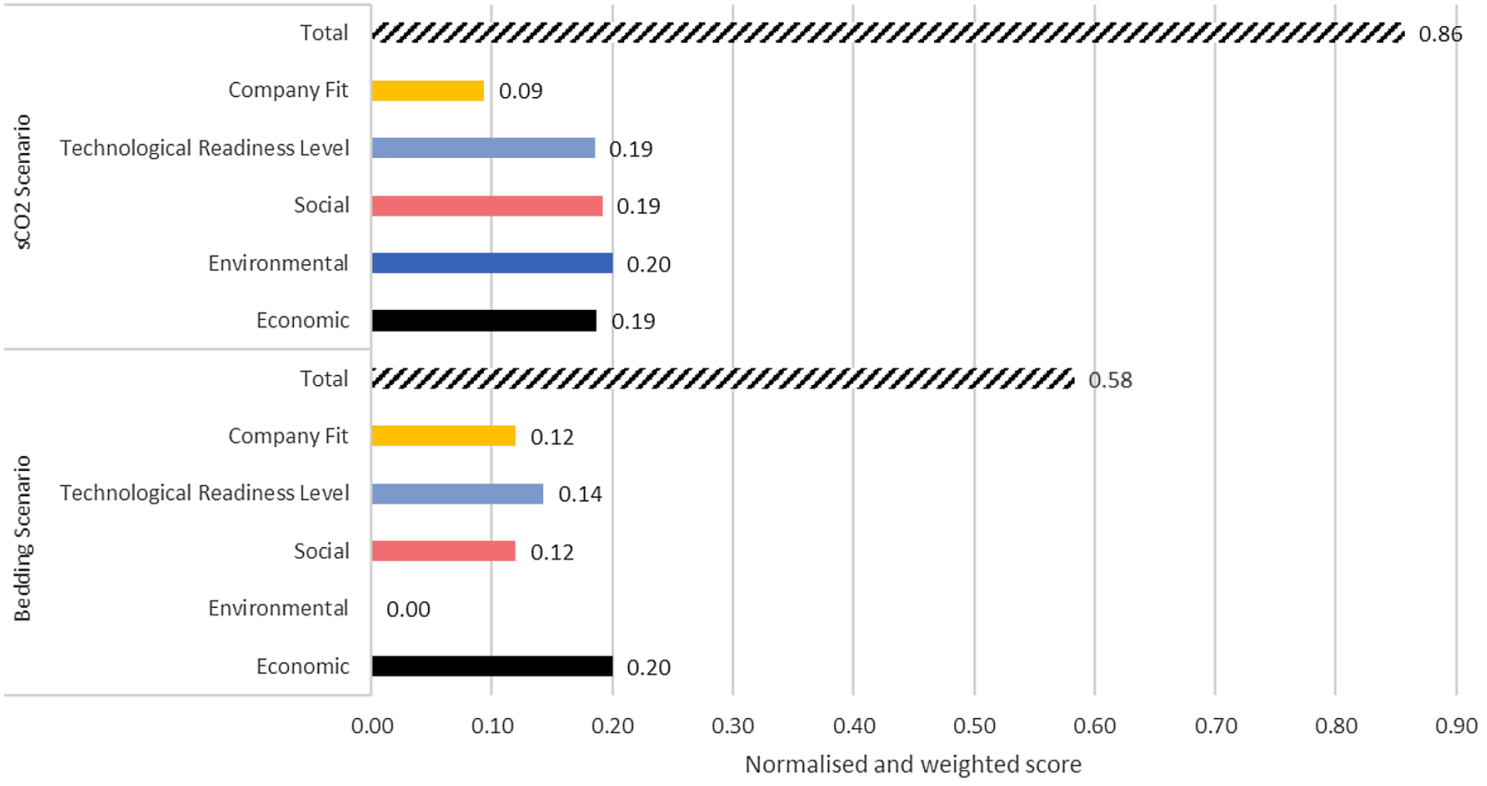

Fig. 4 Normalized, weighted and summed results for the $\mathrm{sCO}_{2}$ extraction and feed supplement scenarios

summed to provide the results shown in Fig. 4 Please refer to the supplementary information document for practical guidance on both weighting and normalisation. Overall, the $\mathrm{sCO}_{2}$ extraction scenario performs best, scoring 0.86 compared to 0.58 for the feed supplement scenario. This is despite performing worse than feed supplement in terms of company fit (due to poor fit with brand image and company expertise) and in terms of economic return, due to the higher capital and running costs outweighing the extra benefit of generating high value wax in addition to pellets suitable for sale as feed. However, $\mathrm{sCO}_{2}$ extraction performed better than feed supplement in terms of technological suitability (particularly due to its higher integrations score) and in terms of social impact (due to enhanced job creation and reduced noise pollution). Both scenarios demonstrated low environmental impact, although as described previously, the fact that the $\mathrm{sCO}_{2}$ extraction scenario scored 0.2 and the animal feed scenario scored 0 reflects the exclusion of impacts from transport, consumption and decomposition in the later (due to inability to obtain the underlying data) and not that it had a worse environmental impact. If this missing data had been included, one would expect to see a higher figure for environmental impact for animal feed, representing better environmental performance.

\section{SWaVI Stage 5: Sensitivity Analysis, Interpretation and Selection of Valorisation Strategy}

Whilst the data analysis suggests that the $\mathrm{sCO}_{2}$ extraction scenario currently presents the overall best fit for Molson
Coors, this conclusion is based upon current financial values which are liable to change over time. Therefore, it is important to analyze the percentage by which all associated financial inputs and outputs may rise or fall before a negative NPV results. For this reason, a full sensitivity analysis was performed for all of the set-up and running costs modelled for each scenario. This was performed as a what-if analysis where the costs for electricity, $\mathrm{CO}_{2}$, water and staff salaries and the benefits received from the sale of wax and animal feed were incrementally increased and decreased by $5 \%$ up to a maximum of $50 \%$ increase and decrease from their current value.

Whilst over the course of each scenario's 20-year life span, costs could rise and fall by more than $50 \%$, this would be unlikely to happen at once and exploring up to $50 \%$ was felt to give a more accurate gauge of susceptibility to dayto-day perturbations. For the feed supplement scenario, the value of barley straw as feed supplement was adjusted in increments of $\pm 5 \%$ (see Fig. 5). In this way, for the $\mathrm{sCO}_{2}$ extraction scenario, we see that because staff salaries and consumables such as energy, $\mathrm{CO}_{2}$ and water make up such a small proportion of overall costs, even a $50 \%$ increase in value would not significantly affect NPV of the scenario (for precise values please refer to the supplementary information document). Equally, whilst the value of the wax sold per $\mathrm{kg}$ is high, because the yield is relatively low compared to the volumes of straw processed, even a $50 \%$ change in value has minimal effect on NPV. However, the scenario is much more susceptible to fluctuations in the value of the pelletised residue sold as animal feed because of the overwhelming 


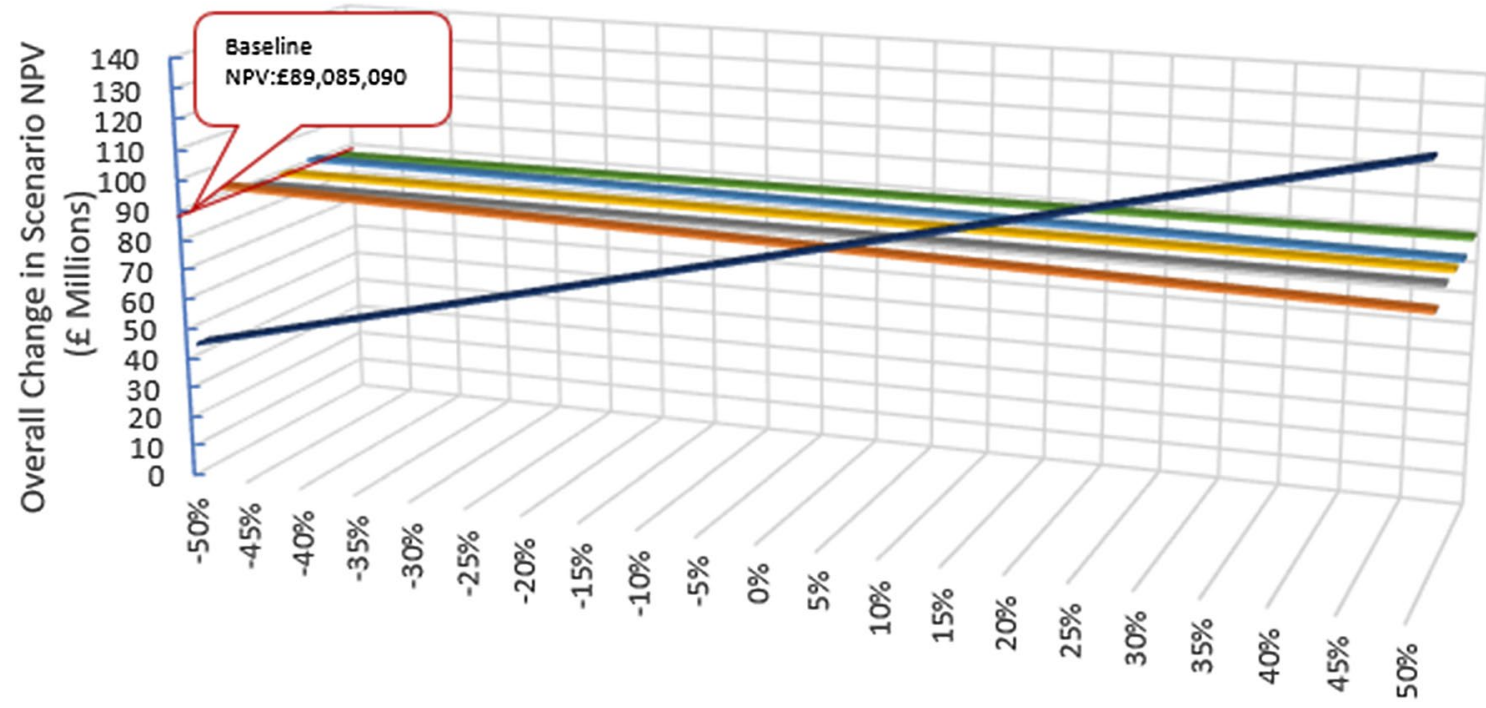

Percentage Change in Component Value

Change in Feed Value $\quad$ Change in Electricity Cost $\square$ Change in Water Cost
Change in $\mathrm{CO} 2$ Cost $\quad \square$ Change in Staff Wages $\quad$ Change in Wax Price

Fig. $5 \mathrm{sCO}_{2}$ extraction scenario sensitivity analysis

volumes sold in this way. As such a $50 \%$ decrease in the value of animal feed could see the NPV of the scenario plummet from a baseline of $£ 89,085,090$ to $£ 43,606,797$ or rise to $£ 134,563,383$. Additionally, unlike the value of the extracted wax whose market equivalent (Carnauba wax Type
3) has shown a consistent increase in global market value in the last six years, the value of barley as animal feed on the spot market has fluctuated significantly over the last six years (see Fig. 6) [55]. In fact, this variability in animal feed price can be seen in AHDB records going back 19 years, the cause

250.00

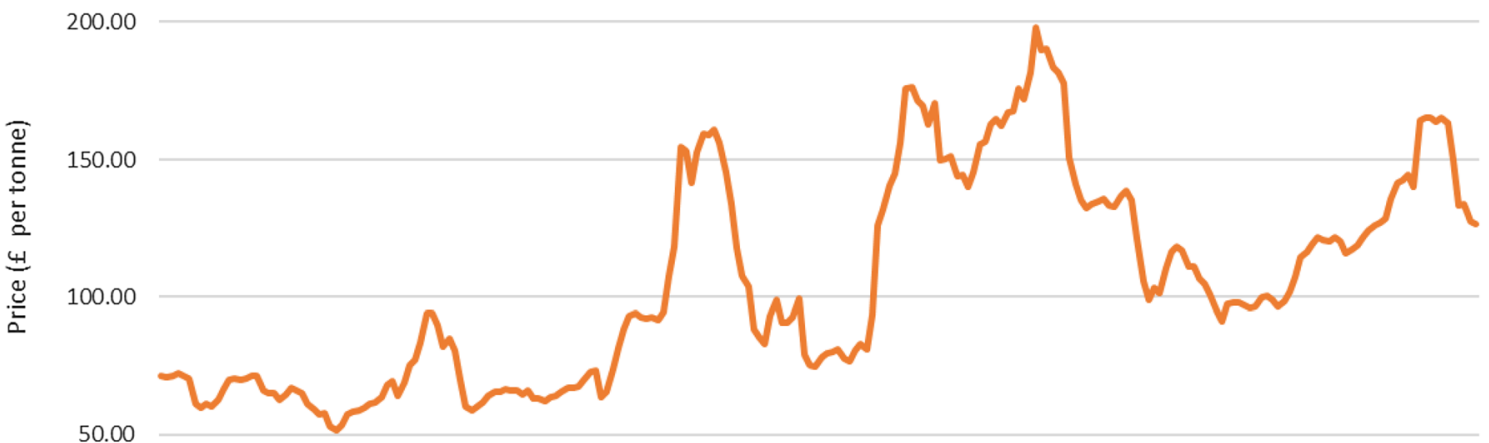

0.00

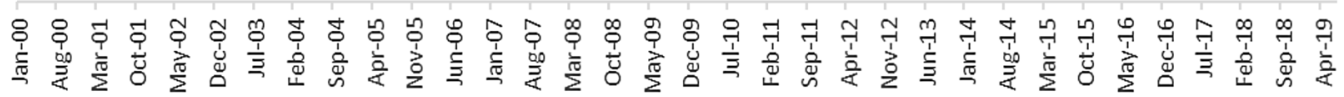

Time (Quarter)

Fig. 6 Fluctuations in UK barley feed prices on the spot market over time [57] 
of which is inextricably linked to weather, both in the UK and abroad from the USA to Ukraine [56]. As this variability is unlikely to cease anytime in the near future, reliance on animal feed prices must be seen as a high-risk investment.

Turning to the scenario where IFBSW is sold for animal feed supplement with no other valorisation steps, a similar principle applies (see Fig. 7) where a 50\% decrease in the value of barley straw as feed supplement would reduce NPV from a baseline of $£ 95,385,354$ to $£ 47,692,677$ and an increase could see it soar to $£ 143,078,030$. In this way, it can be seen that there is a risk that a valorisation scenario where the profit was based solely on the value of IFBSW as animal feed with no alternative income (i.e. wax) could be overly exposed to seasonal fluctuations in supply and demand.

Whilst sensitivity analysis has identified the key economic vulnerabilities of each scenario, it has not taken into account how changing social, environmental and company factors can combine to affect not only the NPV, but also overall viability of each scenario within a wider system of supply chain stakeholders. It is these factors which will now be considered in the discussion section.

\section{Discussion}

Application of the SWaVI framework suggests that $\mathrm{sCO}_{2}$ extraction of wax (with sale of residue as animal feed supplement) appears to offer the most benefits to Molson Coors, scoring 0.86 when the scores for environmental, social and economic performance were weighted, normalized and combined with scores for technological readiness and company fit. In comparison, the existing technique of selling straw as animal feed supplement scored 0.58 . This is not to say that all component scores were higher for the $\mathrm{sCO}_{2}$ extraction scenario as whilst technological readiness and social impact did indeed perform better $(0.19$ and 0.19 respectively in the $\mathrm{sCO}_{2}$ extraction scenario, compared to 0.14 and 0.12 in the animal feed scenario), economic performance and company fit were slightly worse ( 0.19 and 0.09 respectively in the $\mathrm{sCO}_{2}$ extraction scenario, compared to 0.20 and 0.12 respectively in the animal feed scenario). Whilst it may seem that the $\mathrm{sCO}_{2}$ extraction scenario performed best (scoring 0.2 compared to 0 in the animal feed scenario) this is simply because data was unavailable for the aspects of the animal feed scenario where impact would have been generated (e.g. transport, consumption and decomposition).

The advantages for the $\mathrm{sCO}_{2}$ extraction scenario in terms of technological suitability stem from a process that is technologically proven, produces wax and animal feed for which there is high market demand and which has the potential to much more closely integrate with Molson Coors operations as compared to the current sale as animal feed which occurs off-site, so reducing Molson Coors ability to develop the technology. Socially, the $\mathrm{sCO}_{2}$ extraction process results in higher job creation and less odor generation, although with higher traffic generation. Furthermore, whilst this case study assumed three production lines each using lab-scale equipment (see Table 2 in the supplementary information document) and requiring two staff members for each, this would almost certainly be increased to a single, larger and more sophisticated line if Molson Coors decided to implement $\mathrm{sCO}_{2}$ extraction at scale. In this case, the more complex equipment, necessitating greater technical know-how and potential expanding customer and supply base would almost certainly require further highly trained staff, offering further boosts to the local economy. Another social consideration is that it is likely that the pelletized straw residue which is proposed for sale as animal feed, due to its condensed nature, will be more easily packaged for transport, thus reducing traffic generation (and costs) compared to sale in bales as feed supplement.

In terms of environmental performance, relatively low levels of environmental impact were recorded for the actual $\mathrm{sCO}_{2}$ extraction process and environmental impacts relating to transport, consumption and degradation in both scenarios were excluded (although as explained previously, they are
Fig. 7 Straw for animal feed supplement scenario sensitivity analysis

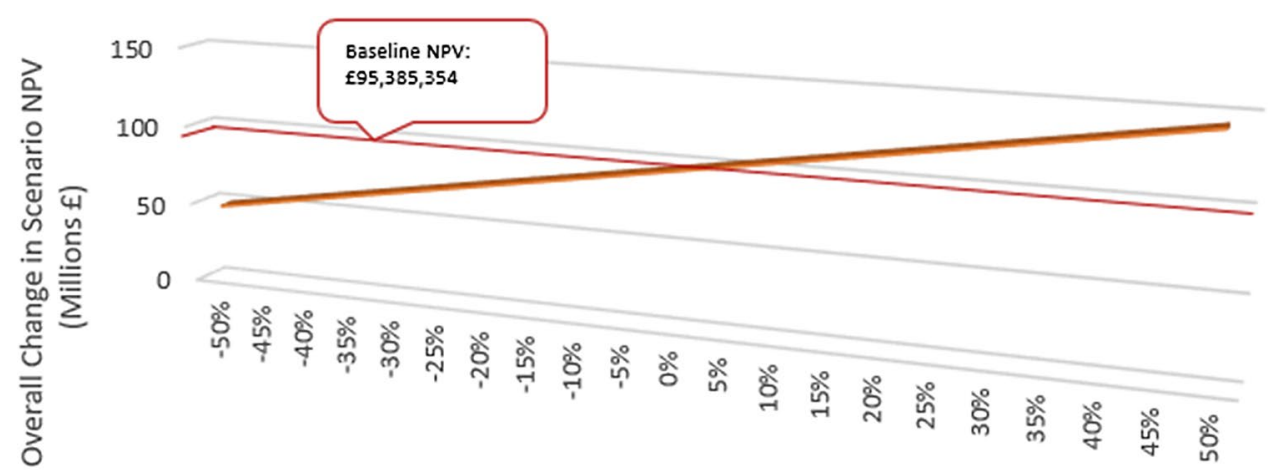

Percentage Change in Component Value 
anticipated to be very similar). This is a lower environmental impact than more conventional methods of wax extraction [29]. Furthermore, the aforementioned assumption that Molson Coors implementing $\mathrm{sCO}_{2}$ extraction at scale would require a larger scale processing line, means that performance in both cases would likely be improved due to reduced energy/water/ $\mathrm{CO}_{2}$ consumption, decreasing set-up costs (currently three small-scale lines are required to manage the annual volume of IFBSW) and likely reducing emissions whilst simultaneously increasing wax yield.

In terms of economic performance, the animal feed scenario performed slightly better and this was due to the absence of major costs involved (0.20 compared to 0.19). This is not to say that the profits are particularly high and the addition of the revenue from wax sales is significant in the $\mathrm{sCO}_{2}$ extraction scenario (see Table 2 in the supplementary information document). Furthermore, sensitivity analysis has indicated that inclusion of revenue from wax in the long term is a more secure source of revenue than if Molson Coors was to rely on animal feed revenue alone. This is primarily because poor weather can significantly increase demand for, and thus the price of, straw for feed partly because it limits yield and partly because it keeps cattle indoors for longer, requiring more feed when they would otherwise be outdoors grazing [36]. On the flip side, in years where weather is good, supply from external markets such as the USA and Ukraine can flood the market, driving prices down. In addition, there is also some evidence that farmers are moving away from reliance on barley straw for feed in the long run, partly due to high transport costs and are finding alternative feed supplement materials, thus further reducing the reliability of this valorisation method for longterm income [23].

Therefore, if the costs of set up could be absorbed (something which is feasible for larger companies such as Molson Coors), the long-term security of wax extraction suggests the $\mathrm{sCO}_{2}$ extraction scenario may be preferable. This position is strengthened if we consider that evidence suggests that demand for waxes, particularly of the Type 3 quality produced from IFBSW (designating suitability for both food and technical processes), is likely to grow as major refiners reduce production of the types of petroleum feedstocks which are suitable for wax production. As such it is likely that we will see the value of wax increase rather than decrease in the future [34-36]. Furthermore, as mentioned previously, it is likely that if Molson Coors were to build a larger scale and more efficient $\mathrm{sCO}_{2}$ extraction line, a higher yield than $1.35 \mathrm{~kg}$ per $90 \mathrm{~kg}$ could be achieved thus pushing up potential revenue from the wax output. Besides process improvements, it is also possible that because the residue from the $\mathrm{sCO}_{2}$ extraction process is in pellet form, its nutritional value could easily be supplemented thereby increasing nutrient value and pellet price. Therefore economically, whilst the $\mathrm{sCO}_{2}$ extraction scenario scored slightly worse at present, a longer-term analysis suggests it is actually superior to the simple sale of IFBSW as animal feed.

As a final discussion point, it was identified that the production of wax does not closely align with Molson Coors' current product offering and nor does the $\mathrm{sCO}_{2}$ extraction process align with company expertise (leading to a low score of just 0.09). However, sale of IFBSW as animal feed did not score much better (at 0.12 ). It is possible that, over time, the challenges of poor brand fit and lack of internal expertise could be overcome internally by Molson Coors. However, an alternative approach could be to make use of the facilities and support offered by the recently formed BioPilots UK consortium. Composed of BEACON (Wales), the Biorenewables Development Centre (BDC-York), the Centre for Process Innovation (CPI-Redcar), IBioIC (Scotland), and The Biorefinery Centre (Norwich), the consortium offers not only the facilities to process $\mathrm{sCO}_{2}$ extraction as part of a broader biorefinery approach, but also awareness of other industrial partners with staff expertise, facilities and experience in establishing confidential, commercial ventures so that Molson Coors might not have to internalize the $\mathrm{sCO}_{2}$ extraction themselves [37].

\section{Concluding Remarks}

The SWaVI framework was designed to improve the management of food waste in the food and drink manufacturing sector by enabling the comparison of multiple valorisation strategies to identify the solutions with the best economic, social, environmental performance, technological maturity and alignment with company goals. The purpose of this paper was to test the application of the framework via a case study with Molson Coors to identify whether the current strategy of using In Field Barley Straw Residue as animal feed is the most sustainable. Analysis of the waste flows associated with the production of barley for malt in the brewing process identified a number of wastes. Of these, the low economic returns and environmental performance of current methods of managing in-field barley straw waste (IFBSW) made it the most promising waste stream for valorisation. Assessment of stakeholders suggested that at current volumes, farmers receiving this straw for feed supplement would be able to find alternative feed at a comparable price. From a regulation perspective, removal of IFBSW for valorisation was unlikely to conflict with environmental permitting or grower subsidies from the Common Agricultural Policy and depending on how the straw was valorized, may actually benefit from government capital allowances on energy efficient appliances. 
A number of possible valorisation options were therefore considered for comparison with the current method of sale as animal feed supplement. Amongst these were the extraction of a number of high value compounds but wax was identified as being potentially the most valuable (with growing market demand), most environmentally friendly (when using a novel process of $\mathrm{sCO}_{2}$ extraction) and the most robust in the sense that value was also gained from the sale of residual pelletised straw for animal feed. Data were collected to assess each scenario based upon economic, environmental, social and technological performance as well as alignment with company strategy. Overall, results suggest that $\mathrm{sCO}_{2}$ extraction had the potential to be a better fit for Molson Coors compared to the current method of selling IFBSW as animal feed supplement. This was due to particularly strong performance in terms of social impact such as reduced noise/odor levels and job creation as well as a high level of technological readiness particularly from a market demand and integration potential perspective. $\mathrm{SCO}_{2}$ extraction performed comparably with feed supplement on economic and environmental grounds although there are some important caveats. However, wider analysis of each scenario beyond their immediate performance revealed a number of factors which are likely to be relevant beyond the food and drink manufacturing sector:

1. Novel valorisation strategies that have only been demonstrated at laboratory scale will often generate a poor initial NPV, due to initial set-up costs and relative inefficiency (i.e. using laboratory scale equipment to process industrial scale volumes), making them seem less competitive. However, if a company were to implement such valorisation scenarios at scale, the equipment would likely better reflect their scale, with significant benefits for efficiency, revenue and environmental impact.

2. Unsurprisingly, novel valorisation scenarios are often likely to score poorly from a company fit perspective because they often require currently unavailable staff expertise, new ways of working and the marketing of a new product. Whilst companies would likely overcome these factors with time, it was also discussed that help from expert bio renewable organisations, such as $\mathrm{BioPi}$ lots UK may well be key here, being able to offer advice to Molson Coors regarding market access and training if they decided to go ahead with their own production site, or, by linking them with external facilities providers if they chose to pursue $\mathrm{sCO}_{2}$ extraction as part of an external biorefinery approach.

As discussed at various points throughout the paper, there are a number of limitations to this work. First and foremost is the assumption, based on the prototype $\mathrm{sCO}_{2}$ extraction system described by Sin, that the entire annual 75,000 ton quantity of IFBSW would be processed in $90-\mathrm{kg}$ batches. Whilst this assumption was necessary to perform accurate Cost-Benefit Analysis and environmental, social and technological readiness assessment, it is unlikely that Molson Coors would use three such systems operating simultaneously when they could instead install a larger (and presumably more efficient) system. However, data on a working system of this scale were unavailable to the authors. Another limitation was the omission of transport data regarding where, exactly, feed supplement straw is currently sent and where hypothetical yields of wax and pelletized animal feed will be sold. This will likely result in significant economic, environmental and social impact for each scenario. With regards to future work, application of the SWaVI framework is currently somewhat restricted by the need for researchers to visit companies and administer the framework in the form of structured interviews. The process could be expedited if the framework could become digitized and available for companies to access online. However, in doing so, new problems would have to be overcome, including enabling companies to access reputable and up-to-date environmental databases to analyze their chosen environmental indicators without the need for expert assistance.

Acknowledgements This research was funded by the Engineering and Physical Sciences Research Council (EPSRC) [Grant Reference EP/ P008771/1]. The authors thank Thomas Dugmore from the University of York for his support to define the initial stages of this work and Molson Coors to provide data and thoughts about the IFBSW valorisation.

\section{Compliance with Ethical Standards}

Conflicts of interest The authors declare no conflict of interest.

Open Access This article is distributed under the terms of the Creative Commons Attribution 4.0 International License (http://creativeco mmons.org/licenses/by/4.0/), which permits unrestricted use, distribution, and reproduction in any medium, provided you give appropriate credit to the original author(s) and the source, provide a link to the Creative Commons license, and indicate if changes were made.

\section{References}

1. Wra, P.: Food Surplus and Waste in the UK-Key Facts. WRAP, London (2018)

2. Taylor, A., Loopstra, R.: Too Poor to Eat. Food Insecurity in the UK. The Food Foundation, London (2016)

3. Lipinski, B., O'Connor, C., Hanson, C.: SDG Target 123 on Food Loss and Waste: 2016 Progress Report. Champions, Washington, DC (2016)

4. Lee, D.: Food Statistics Pocketbook. Defra, London (2017)

5. Parfitt, J., Woodham, S., Swan, E., Castella, T., Parry, A.: Quantification of Food Surplus, Waste, and Related Materials in the Grocery Supply Chain. Final Report v2. 2016

6. WRAP: Courtauld Commitment 3: Delivering Action on Waste. WRAP, London (2017) 
7. Hanson, C., Mitchell, P.: The Business Case for Reducing Food Loss and Waste. WRAP, London (2017)

8. Mirabella, N., Castellani, V., Sala, S.: Current options for the valorization of food manufacturing waste: a review. J. Clean. Prod. 65, 28-41 (2014)

9. Kwan, T.H., Pleissner, D., Lau, K.Y., Venus, J., Pommeret, A., Lin, C.: Techno-economic analysis of a food waste valorization process via microalgae cultivation and co-production of plasticizer, lactic acid and animal feed from algal biomass and food waste. Bioresour. Technol. 198, 292-299 (2015)

10. Dimou, C., Vlysidis, A., Kopsahelis, N., Papanikolaou, S., Koutinas, A.: Techno-economic evaluation of wine lees refining for the production of value-added products. Biochem. Eng. J. 116, 157-165 (2016)

11. Tesfaye, T., Johakimu, J.K., Chavan, R.B., Sithole, B., Ramjugernath, D.: Valorisation of mango seed via extraction of starch: preliminary techno-economic analysis. Clean Technol. Environ. Policy 20(1), 81-94 (2018)

12. Bernstad, A., La Cour Jansen, J.: A life cycle approach to the management of household food waste-a Swedish full-scale case study. Waste Manag. 31(8), 1879-1896 (2011)

13. Iacovidou, E., Ohandja, D.G., Voulvoulis, N.: Food waste codigestion with sewage sludge-realising its potential in the UK. J. Environ. Manag. 112, 267-274 (2012)

14. Stone, J., Garcia-Garcia, G., Rahimifard, S.: Development of a pragmatic framework to help food and drink manufacturers select the most sustainable food waste valorisation strategy. J. Environ. Manag. 247, 425-438 (2019)

15. Iacovidou, E., Voulvoulis, N.: A multi-criteria sustainability assessment framework: development and application in comparing two food waste management options using a UK region as a case study. Environ. Sci. Pollut. Res. 25(36), 35821-35834 (2018)

16. Kapepula, K.M., Colson, G., Sabri, K., Thonart, P.: A multiple criteria analysis for household solid waste management in the urban community of Dakar. Waste Manag. 27(11), 1690-1705 (2007)

17. DEFRA: Farming Statistics-First Estimates of UK Wheat and Barley Production, p. 2018. DEFRA, London (2018)

18. Zhou, M.X.: Barley Production and Consumption Genetics and Improvement of Barley Malt Quality, pp. 1-17. Springer, Berlin (2009)

19. Patsios, S., Kontogiannopoulos, K., Mitrouli, S., Plakas, A., Karabelas, J., Sotiris, P., Konstantinos, K., Soultana, M., Konstantinos, P., Anastasios, J.: Characterisation of agricultural waste co- and by-products. Agrocycle (2016)

20. Herwijnen, M.: Weighted Summation (WSum) (2006)

21. Garcia-Garcia, G., Stone, J., Rahimifard, S.: Opportunities for waste valorisation in the food industry - a case study with four UK food manufacturers. J. Clean. Prod. 20(211), 1339-1356 (2019)

22. Julian, B., Gillian, I., McDowell, M.: Straw and Forage Study. SRUC and Scottish Government, London (2018)

23. Meyer, A.K., Ehimen, E.A., Holm-Nielsen, J.B.: Future European biogas: animal manure, straw and grass potentials for a sustainable European biogas production. Biomass Bioenerg. 111, 154-164 (2018)

24. UK Government: Environmental Taxes, Reliefs and Schemes for Businesses. https://www.gov.uk/green-taxes-and-reliefs/capitalallowances-on-energyefficient-items (2018). Accessed 5 Mar 2019

25. UK Government: Landmark Agriculture Bill to deliver a Green Brexit. https://www.gov.uk/government/news/landmark-agricultur e-bill-to-deliver-a-green-brexit. Accessed 5 Mar 2019

26. European Parliament Council: Directive 2008/1/EC of the European Parliament and of the Council of 15 January 2008 Concerning Integrated Pollution Prevention and Control. European Parliament Council, Brussels (2008)
27. González-García, S., Morales, P.C., Gullón, B.: Estimating the environmental impacts of a brewery waste-based biorefinery: bioethanol and xylooligosaccharides joint production case study. Ind. Crops Prod. 123, 331-340 (2018)

28. Laborel-Préneron, A., Magniont, C., Aubert, J.E.: Characterization of barley straw, hemp shiv and corn cob as resources for bioaggregate based building materials. Waste Biomass Valoriz. 9(7), 1095-1112 (2018)

29. Sin, E.: The extraction and fractionation of waxes from biomass. https://etheses.whiterose.ac.uk/3123 (2012)

30. Styles, D., Dominguez, E.M., Chadwick, D.: Environmental balance of the UK biogas sector: an evaluation by consequential life cycle assessment. Sci. Total Environ. 560, 241-253 (2016)

31. Grand View Research: Wax Market Size \& SharelGlobal Industry Research Report, 2018-2025. Grand View Research, Pune (2019)

32. Research and Markets: Wax Market by Type and ApplicationGlobal Opportunity Analysis and Industry Forecast, 2017-2023. Research and Markets, London (2019)

33. Sin, E., Marriott, R., Hunt, A.J., Clark, J.H.: Identification, quantification and Chrastil modelling of wheat straw wax extraction using supercritical carbon dioxide. C R Chim 17(3), 293-300 (2014)

34. Kim, M.H., Song, Y.E., Song, H.B., Kim, J.W., Hwang, S.J.: Evaluation of food waste disposal options by LCC analysis from the perspective of global warming: Jungnang case. South Korea. Waste Manag. 31(9-10), 2112-2120 (2011)

35. Lundie, S., Peters, G.M.: Life cycle assessment of food waste management options. J. Clean. Prod. 13(3), 275-286 (2005)

36. Parfitt, J., Stanley, C., Thompson, L.: Guidance for Food and Drink Manufacturers and Retailers on the Use of Food Surplus as Animal Feed. Version 1.0 (2016)

37. WRAP: Specification for Whole Digestate, Separated Liquor and Separated Fibre Derived from the Anaerobic Digestion of SourceSegregated Biodegradable Material. WRAP, London (2014)

38. Vandermeersch, T., Alvarenga, R.A., Ragaert, P., Dewulf, J.: Environmental sustainability assessment of food waste valorization options. Resour. Conserv. Recycl. 87, 57-64 (2014)

39. Salemdeeb, R., Zu Ermgassen, E.K., Kim, M.H., Balmford, A., Al-Tabbaa, A.: Environmental and health impacts of using food waste as animal feed: a comparative analysis of food waste management options. J. Clean. Prod. 140, 871-880 (2017)

40. Amienyo, D., Azapagic, A.: Life cycle environmental impacts and costs of beer production and consumption in the UK. Int. J. Life Cycle Assess. 21(4), 492-509 (2016)

41. Chong, Y.T., Teo, K.M., Tang, L.C.: A lifecycle-based sustainability indicator framework for waste-to-energy systems and a proposed metric of sustainability. Renew. Sustain. Energy Rev. 56, 797-809 (2016)

42. Den Boer, J., Den Boer, E., Jager, J.: LCA-IWM: a decision support tool for sustainability assessment of waste management systems. Waste Manag. 27(8), 1032-1045 (2007)

43. Kythreotou, N., Florides, G., Tassou, S.A.: A review of simple to scientific models for anaerobic digestion. Renew. Energy 71, 701-714 (2014)

44. Integrated Pollution, Prevention and Control: Reference Document on Best Available Techniques for the Waste Treatments Industries. Integrated Pollution, Prevention and Control, Rome (2006)

45. Den Boer, E., Brouwer, F., Schroten, A., Van Essen, H.: Are trucks taking their toll? The environmental, safety and congestion impacts of lorries in the EU. European Commission, Delft (2009)

46. Buksti, M., Fremming, T., Juul, S., Grandjean, F., Christensen, S.: Surplus Food Redistribution System. Feasibility Final Report (2015)

47. Kijak, R., Moy, D.: A decision support framework for sustainable waste management. J. Ind. Ecol. 8(3), 33-50 (2004) 
48. Garcia-Garcia, G.: Development of a framework for sustainable management of industrial food waste. Doctoral dissertation, Loughborough University

49. HORIZON 2020: Work Programme 2014-2015. Technology Readiness Levels (TRL), Brussels (2014)

50. Solberg Hjorth, S., Brem, A.: How to assess market readiness for an innovative solution: the case of heat recovery technologies for SMEs. Sustainability 8(11), 1152 (2016)

51. Sauser, B., Verma, D., Ramirez-Marquez, J., Gove, R.: From TRL to SRL: the concept of systems readiness levels. In: Conference on Systems Engineering Research, Los Angeles, CA, pp. 1-10 (2006)

52. Paun, F.: 'Demand Readiness Level' (DRL): A New Tool to Hybridize Market Pull and Technology Push Approaches-Introspective Analysis of the New Trends in Technology transfer practices. University of the Littoral Opal Coast, Dunkerque (2011)

53. WRAP: Valorization Business Case Toolkit. https://www.wrapc ymru.org.uk/register-download-valorisation-business-case-toolk it (2018)

\section{Affiliations}

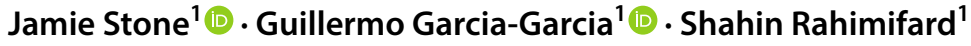

Shahin Rahimifard

S.Rahimifard@lboro.ac.uk
54. Garcia-Garcia, G., Rahimifard, S.: Life-cycle environmental impacts of barley straw valorisation, resources, conservation and recycling. Resour. Conserv. Recycl. 149, 1-11 (2019). https://doi. org/10.1016/j.resconrec.2019.05.026

55. AHDB: Feed prices and markets. https://dairy.ahdb.org.uk/marke t-information/farm-expenses/feed-prices/feed-prices-and-marke ts/\#.XTyGkuhKhPY (2019)

56. Farmers Weekly: Straw Prices Fall as Supply Fears Recede. Farmers Weekly. https://www.fwi.co.uk/business/markets-and-trends/ input-prices/straw-prices-fall-as-supply-fears-recede (2019)

Publisher's Note Springer Nature remains neutral with regard to jurisdictional claims in published maps and institutional affiliations.
1 Centre for Sustainable Manufacturing and Recycling Technologies, Loughborough University, Leicestershire LE11 3TU, UK 